\title{
ENTREVISTA
}

\section{Do indigenismo empresarial à catástrofe bolsonarista: uma entrevista com o antropólogo Stephen Grant Baines}

\section{From entrepreneurial indigenism to the catastrophy of Bolsonaro's policies: an interview with the anthropologist Stephen Grant Baines}

Leonardo Barros Soares - Doutor em Ciência Política pela Universidade Federal de Minas Gerais (UFMG). Professor Adjunto do Programa de Pós-Graduação em Ciência Política (PPGCP) da Universidade Federal do Pará (UFPA).E-mail: leobarros@ufpa.br

Stephen Grant Baines - Doutor em Antropologia pela Universidade de Brasília (UnB). Professor Titular do Departamento de Antropologia da UnB. E-mail: stephengbaines@gmail.com

\section{Resumo}

O antropólogo Stephen Grant Baines é Professor Titular do Departamento de Antropologia da Universidade de Brasília, pesquisador de produtividade do Conselho Nacional de Desenvolvimento Científico e Tecnológico e coordenador do Laboratório e Grupo de Estudos de Relações Interétnicas (LAGERI/UnB). Nesta entrevista, percorremos seus mais de trinta anos de carreira acadêmica, evidenciando sua trajetória profissional e pessoal e seus temas de pesquisa atual. Estes se concentram no estudo de estilos de etnologia indígena numa perspectiva internacional comparada, povos indígenas em fronteiras internacionais e da existência de indígenas encarcerados em Roraima. Por fim, o professor Baines apresenta sua avaliação do atual momento da política indigenista no Brasil sob o governo de Jair Bolsonaro.

\section{Palavras-chave}

Indigenismo. Povos indígenas. Estilos de antropologia. Pesquisa comparada.

\begin{abstract}
Anthropologist Stephen Grant Baines is Professor in the Department of Anthropology at the University of Brasilia (UnB), a productivity researcher at the National Council for Scientific and Technological Development (CNPq) and coordinator of the Laboratory and Group for the Study of Interethnic Relations (LAGERI / UnB). In this interview, we covered his more than thirty years of academic career, showing his professional and personal trajectory and his current research themes. These focus on the study of styles of ethnology in a comparative international perspective, indigenous peoples on international borders and the existence of incarcerated indigenous individuals in Roraima. Finally, Professor Baines presents his assessment of the current moment of indigenous politics in Brazil under the government of Jair Bolsonaro.
\end{abstract}

\section{Keywords}

Indigenism. Indigenous peoples. Styles of anthropology. Comparative research. 


\section{Leonardo Barros Soares: Gostaria que o senhor começasse a entrevista narrando tua trajetória profissional e acadêmica de forma ampla. Como foi a decisão de vir para o Brasil e fazer aqui o doutorado?}

Stephen Grant Baines: Nasci e fui criado em Londres, Inglaterra. Desde jovem acompanhei notícias sobre o Brasil e me cativou a região amazônica da América do Sul com as maiores florestas tropicais do mundo. Após concluir a graduação em Língua e Literatura Árabe e Sociologia da Religião na Universidade de Leeds, Inglaterra em 1971, queria conhecer um pouco do mundo antes de seguir para a pós-graduação e viajei por vários países no Oriente Médio, Norte da África e sul da Ásia, além da Europa, e depois nas Américas, dando aulas de inglês para me sustentar. Nas minhas viagens pelas Américas, interessei-me muito nos povos indígenas e, ao chegar ao Brasil pela primeira vez em abril de 1975 no Rio Grande do Sul, segui à Amazônia e comecei a acompanhar as notícias sobre povos indígenas. Uma experiência que marcou meu interesse em realizar pesquisas em antropologia foi em junho de 1975, quando segui de Manaus aos limites do território do povo Waimiri-Atroari. Interessado em saber mais sobre este povo indígena, segui pela rodovia BR-174, que liga Manaus a Boa Vista, em junho de 1975 ao Igarapé Santo Antônio do Abonari nos limites do território indígena.

Cheguei aos limites das terras do povo indígena Waimiri-Atroari, no momento em que seu território estava sendo cortado pela rodovia BR-174, o que acarretou uma mortalidade enorme entre este povo indígena, reduzidos de 2 ou 3 mil pessoas nas primeiras décadas do século XX a 332 indivíduos em 1983. O comandante do $6^{\circ}$ Batalhão de Engenharia de Construção (BEC) concordou em me levar de carona até o Igarapé Santo Antônio do Abonari, na condição de que eu voltasse no dia seguinte. Dormi no quartel do $6^{\circ} \mathrm{BEC}$ em Abonari e conversei com os soldados sobre seus contatos com os Waimiri-Atroari. No dia seguinte, o comandante providenciou transporte do Exército para me levar os $6 \mathrm{~km}$ até a ponte sobre o Igarapé Santo Antônio do Abonari, nos limites da área interditada para a chamada "atração e pacificação dos Waimiri-Atroari”.

Em Manaus, conheci o então antropólogo do Departamento de Antropologia (DAN) da Universidade de Brasília (UnB), professor Peter Silverwood-Cope que, na época, estava trabalhando em projeto de saúde indígena em Iauaretê no Alto Rio Negro. Ele me informou que se eu fizesse um curso como atendente de enfermagem para ter uma qualificação brasileira aproveitável pela Fundação Nacional do Índio (FUNAI), poderia solicitar minha contratação pela FUNAI, 
e me apresentou ao então Delegado Regional da FUNAI em Manaus, Francisco Mont'alverne Pires, que me informou que precisaria ter o visto permanente no Brasil para poder ser contratado pela FUNAI. Passei dois anos em Manaus, onde completei curso de atendente de enfermagem na Unidade Sanitária Morro da Liberdade, e dava aulas de inglês para me sustentar.

Em 1977, sem ter obtido o visto permanente no Brasil, segui para a Venezuela, onde tentei trabalhar junto a povos indígenas. Após três meses de espera, em que viajei ao território do povo indígena Panare, meu pedido para visto de trabalho foi negado pelo Departamento Indigenista em que o diretor, coronel do exército, insistiu que estrangeiros não poderiam trabalhar em área de fronteira. Segui para os Estados Unidos, México, Nova Zelândia e Austrália, países em que fui aceito para ingressar em programas de mestrado em antropologia. Entretanto, sem disponibilidade de bolsas de estudo e sem possibilidade de conseguir o visto de trabalho para poder coadunar trabalho e estudos, não foi possível iniciar o mestrado nesses países.

Em 1979, fui aprovado na University of Cambridge, Inglaterra para cursar o Mestrado sob a orientação do professor Alan MacFarlane, com coorientação do professor Stephen Hugh-Jones, com apoio de uma bolsa de estudos da University of Leeds onde eu havia realizado a graduação. Enquanto estava cursando o Mestrado em Antropologia Social na University of Cambridge, Inglaterra, solicitei uma bolsa de estudos no Brasil ao Ministério de Relações Exteriores que, na época, oferecia uma bolsa de estudos a cada ano para candidatos de nacionalidade britânica que queriam realizar cursos de pós-graduação no Brasil. A concessão desta bolsa de estudos pelo governo brasileiro por meio da Embaixada do Brasil em Londres determinou, definitivamente, minha trajetória acadêmica, e o Brasil como país onde realizei o doutorado em antropologia, e consolidei a minha carreira em um dos maiores centros de excelência acadêmica em antropologia no Brasil, a Universidade de Brasília.

Realizei o doutorado no DAN/UnB (1981-1988) sob a orientação de um dos pesquisadores mais conhecidos na área de etnologia indígena, professor Julio Cezar Melatti. Consolidei meu conhecimento sobre a antropologia, especializeime em etnologia indígena e realizei uma pesquisa de campo de longa duração (18 meses em comunidades indígenas) junto ao povo indígena Waimiri-Atroari, na região Norte-Amazônica. Além do apoio incansável do professor Melatti, contei também com o apoio inestimável do professor Roberto Cardoso de 
Oliveira e outros professores do DAN/UnB. Após realizar concurso público no Departamento de Antropologia da UnB em 1988, fui contratado em 1989 e a partir de 1990, recebi convite do professor Roberto Cardoso para participar do seu projeto de pesquisa sobre "Estilos de Antropologia" na Universidade Estadual de Campinas (UNICAMP), com uma proposta de pesquisa comparativa em etnologia indígena no Brasil e na Austrália. Posteriormente, a parceria com o professor Roberto Cardoso de Oliveira se consolidou com a sua volta ao Centro de Pesquisa e Pós-Graduação sobre as Américas (CEPPAC/UnB - atualmente o Departamento de Estudos Latino-Americanos - ELA/UnB), quando me convidou a cocoordenar um projeto de pesquisa sobre "Nacionalidade e Etnicidade em Áreas de Fronteira", em que apresentei uma proposta de pesquisa junto aos povos indígenas Makuxi e Wapichana na fronteira Brasil-Guiana.

Cheguei a Brasília em julho de 1980 como aluno especial e, em março de 1981, iniciei meus estudos na primeira turma de doutorado do DAN/UnB. Quando aluno de doutorado no $\mathrm{DAN} / \mathrm{UnB}$, animado pelo ambiente estimulante da antropologia praticado no Brasil, já me interessei pela possibilidade de seguir carreira acadêmica no Brasil e tentei, novamente, conseguir o visto permanente. Após concluir a tese de doutorado no final de 1987 e defendê-la em março de 1988, passei o período de março de 1988 a maio de 1989 no setor de Antropologia do Museu Paraense Emílio Goeldi em Belém do Pará, então do Conselho Nacional de Desenvolvimento Científico e Tecnológico (CNPq), como pesquisador bolsista na modalidade de Bolsa de Desenvolvimento Regional, quando publiquei minha tese de doutorado em forma de livro, É a FUNAI que sabe: a frente de atração Waimiri-Atroari (BAINES, [1988] 1991a).

\section{[LBS]: O senhor poderia explicar, de forma mais aprofundada, seu tema de doutorado e quais foram suas principais conclusões?}

[SGB]: Meu tema de doutorado na área de etnologia indígena foi, inicialmente, um estudo etnográfico sobre o povo Waimiri-Atroari dentro da tradição da etnologia que se faz no Brasil de abordar tantos aspectos da sociedade Waimiri-Atroari quanto a situação de contato interétnico em que se encontravam. Entre janeiro de 1982 e agosto de 1985, realizei dezoito meses de pesquisa de campo junto aos Waimiri-Atroari, dividida em várias etapas. Apliquei os conhecimentos adquiridos em etnologia indígena no $\mathrm{DAN} / \mathrm{UnB}$ para elaborar uma tese usando noções como "linguagem de dominação", "discursos de dominação" e posteriormente, após a instalação do Programa Waimiri-Atroari (PWA), a partir de abril de 1987, a noção 
de "autodeterminação dirigida" e "indigenismo empresarial" para caracterizar uma política indigenista subordinada aos interesses de grandes empresas, da construção da Usina Hidrelétrica de Balbina (ELETRONORTE) e de mineradoras que atuavam na Mina de Pitinga (Mineração Taboca S.A.) em terras desmembradas das terras indígenas delimitadas pelo sertanista Gilberto Pinto Figueiredo Costa, em 1971, após uma manipulação cartográfica que retirou 40\% da terra indígena original para favorecer essas duas empresas em novembro de 1981. Nesta nova política indigenista, a FUNAI passou suas obrigações de administrar esta terra indígena, como órgão indigenista do Estado, por meio de um convênio entre a FUNAI e a ELETRONORTE, a uma organização não governamental, o Programa Waimiri-Atroari, cuja sede se localiza no edifício sede da ELETRONORTE em Brasília. Desta maneira, privatizou-se a administração indigenista do povo WaimiriAtroari por um programa atrelado aos interesses de uma empresa que provocou a inundação de vastas extensões do seu território tradicional.

Encontrei na etnologia indígena que se faz no Brasil, sobretudo nos estudos sobre o contato interétnico, subsídios teóricos para abordar a situação crítica em que se encontravam os Waimiri-Atroari, seu território cortado pela rodovia BR-174, e, posteriormente, com uma porção desmembrada para servir os interesses tanto da ELETRONORTE que, em 1987, veio a inundar uma vasta área na parte sul da área desmembrada, quanto da Mineração Taboca que ocupou, de forma maciça, vasta área na parte norte desmembrada. Encontrei subsídios, sobretudo, nos estudos sobre o contato interétnico e a noção de fricção interétnica de Roberto Cardoso de Oliveira ([1964] 1981), entretanto, revisando a noção para explicar a situação empírica da minha pesquisa de campo, em que os funcionários indígenas da frente de atração da FUNAI transmitiam aos capitães Waimiri-Atroari todas as contradições e ambiguidades inerentes à identidade de "índio civilizado" e "caboclo" (BAINES, [1988] 1991a). Lançaram mão da retórica do movimento indígena, de serem, junto com os Waimiri-Atroari, "índios também”, unidos na luta política contra os "brancos". Porém, manipulavam as ambiguidades das identidades étnicas acionadas na Frente de Atração Waimiri-Atriari (FAWA) para seu próprio proveito. Ora se identificaram como "índios" contra os "brancos", ora como "índios civilizados" ou "caboclos" em oposição a "índios WaimiriAtroari" / "índios bravos" vistos pejorativamente, ora como "peãos da FUNAI" em oposição ao "chefe branco", conforme o contexto e a intenção por meio de discursos de dominação (BAINES, [1988] 1991a). Estas categorias foram impostas por meio de relações interétnicas desmedidamente assimétricas de sujeição-dominação (CARDOSO DE OLIVEIRA, [1964] 1981), acionando uma 
linguagem de dominação, e discursos de dominação que redefiniam a realidade para os Waimiri-Atroari (BAINES, [1988] 1991a). Enquanto estava redigindo minha tese de doutorado na UnB, o Programa Waimiri-Atroari (PWA FUNAI/ ELETRONORTE), criado em abril de 1987, posterior à minha pesquisa de campo para o doutorado, assumiu a administração indigenista na Terra Indígena Waimiri-Atroari. Tratava-se de um programa indigenista de assistência divulgado por meio de campanhas de propaganda em nível nacional e internacional como um caso exemplar de indigenismo, apoiado por grandes empresas e com recursos do Banco Mundial. A Mineração Taboca e outras empresas mineradoras subsidiárias do então Grupo Paranapanema, abriram a mina de Pitinga, que se tornou uma das maiores minas de cassiterita (minério de estanho) do mundo, numa área que foi posteriormente desmembrada do território dos Waimiri-Atroari em 1981, por meio de manipulações cartográficas (BAINES, 1991a [1988], 1991b, 1999).

No mesmo período, a ELETRONORTE construiu a Usina Hidrelétrica de Balbina, inundando uma área de cerca de 2.928,5 km2 (BAINES, 2000) que foi desapropriada da Terra Indígena original dos Waimiri-Atroari. Este exemplo revela:

uma nova estratégia das grandes empresas de mineração em colaboração com o Estado - favorecer a demarcação e homologação da área indígena e exercer seu poder econômico para aliciar as novas lideranças indígenas a assinar acordos diretos entre as comunidades indígenas e as empresas, em nome de uma "autodeterminação indígena" (BAINES, 1993, p. 239).

Em junho de 1989, na véspera da minha "expulsão" da Terra Indígena, tramada por funcionários do PWA, acordos foram assinados entre o Grupo Paranapanema e líderes Waimiri-Atroari, dando direitos exclusivos à Mineração Taboca para pesquisa e lavra de minérios na Terra Indígena Waimiri-Atroari. Contudo, estes acordos foram suspensos enquanto não houvesse legislação complementar para regulamentar a pesquisa e lavra de mineração em terras indígenas.

A Terra Indígena Waimiri-Atroari serviu como um modelo empresarial para o planejamento de estratégias para a implantação "regularizada" de grandes projetos de desenvolvimento regional em terras indígenas na Amazônia, tanto de mineração quanto de Usinas Hidrelétricas, e influenciou na própria formulação da Constituição durante o ano de 1987, com forte lobby das empresas mineradoras lideradas pelo Grupo Paranapanema. Este lobby conseguiu, no texto constitucional, legalizar a mineração em terras indígenas a empresas mineradoras privadas.

A experiência de pesquisa de campo para o doutorado e para depois dele apresentou-se como campo privilegiado para examinar as estratégias de grandes empresas para se adaptarem aos direitos indígenas incorporados na Constituição 
Brasileira de 1988. O Programa Waimiri-Atroari passou a ser usado em publicidade para justificar a implantação de usinas hidrelétricas em territórios indígenas na região amazônica, incorporando as lideranças Waimiri-Atroari como porta-vozes da propaganda. Enquanto no período da ditadura militar as grandes empresas invadiam territórios indígenas, criando fatos consumados que foram posteriormente legalizados, uma nova estratégia adotada após a nova Constituição era de criar simulações de relações interétnicas harmoniosas entre as empresas e os povos indígenas. Com as imagens de indígenas que apoiam os programas indigenistas, o discurso do seu supervisor de que o Programa WaimiriAtroari "conseguiu colocar em prática o que todos os indigenistas sonhavam" combina bem com a declaração do presidente da ELETRONORTE de que a Usina Hidrelétrica Belo Monte (que seria uma das maiores do mundo) é a obra de seus sonhos, para tentar reverter as críticas e acelerar a aprovação de mais megaprojetos de usinas hidrelétricas na região amazônica.

Na minha tese de doutorado, defendida na UnB em março de 1988, realizei uma etnografia de uma frente de atração da FUNAI no momento histórico antes de os Waimiri-Atroari serem incorporados dentro de um indigenismo empresarial do Programa Waimiri-Atroari, criado em abril de 1987, seis meses antes do fechamento das comportas da Usina Hidrelétrica de Balbina e inundação de uma vasta área do território tradicional deste povo indígena. Iniciei o doutorado com projeto de pesquisa que focalizava o contato interétnico a partir da noção de "fricção interétnica" de Cardoso de Oliveira ([1964] 1981). Em muitos trabalhos que seguem o modelo de fricção interétnica, as duas populações do sistema interétnico (CARDOSO DE OLIVEIRA, 1978, p. 85) são tomadas como dois grupos empíricos de "índios" e "brancos". Na Frente de Atração Waimiri-Atroari, um contingente grande dos funcionários identificava-se como "índio" e muitos deles acionavam, em alguns contextos, um discurso indigenista que invertia a ideologia hegemônica, valorizando a categoria genérica de "índio" e desprezando a de "branco". Acionavam esse discurso como estratégia para incentivar os Waimiri-Atroari a rejeitar indivíduos que os mesmos funcionários "índios" classificaram como "brancos". Por toda a tese de doutorado, focalizei as relações sociais de sujeição-dominação desmedidamente assimétricas estabelecidas entre os agentes da sociedade nacional e os Waimiri-Atroari.

[LBS]: Quais convergências o teu trabalho tem com relação a outros campos disciplinares, tais como a história e a ciência política? 
[SGB]: Qualquer pesquisa etnográfica junto a povos indígenas é, por definição, uma "antropologia histórica", nas palavras do professor João Pacheco de Oliveira, pois é impossível compreender um povo indígena sem estudar sua história, incluindo a sua história de contato com a sociedade nacional. No caso dos Waimiri-Atroari, há contatos interétnicos com diversos segmentos da sociedade nacional documentados pelo menos desde o século XVIII, além de haver lacunas na sua história documentada, na época dos "descimentos" e "guerras justas", com a implementação de políticas de não documentar a violência e os massacres, oficialmente ilegais, perpetrados contra os povos indígenas pelas expedições escravistas empreendidas tanto pelo governo colonial quanto por particulares, disfarçadas sob o nome de "guerras justas". Entretanto, uma longa história de invasões do território dos Waimiri-Atroari, e repetidos massacres e atrocidades, está muito bem documentada desde meados do século XIX. A ciência política também contribui muito aos estudos sobre povos indígenas, pois é impossível compreender a situação em que vive uma população indígena sem levar em consideração a conjuntura política maior do país em que seus territórios estão inseridos e do mundo, que os subordina em situações coloniais influenciadas por interesses globalizados.

Entretanto, a etnologia indígena tem sua contribuição específica para os estudos junto a povos indígenas por se fundamentar em pesquisa de campo de longa duração em que o antropólogo acompanha o povo indígena com quem realiza pesquisa em relações face a face com pessoas de carne e osso e aprende a língua indígena, além de participar diretamente dos dilemas frequentemente trágicos que o povo indígena está passando. Porém, uma etnologia indígena que não leva em consideração uma perspectiva mais ampla da história e da ciência política seria muito limitada, em situações em que povos indígenas estão diretamente envolvidos em eventos mundiais.

\section{[LBS]: Como o senhor analisa, historicamente, a história da relação dos povos indígenas com o aparato burocrático estatal no Brasil?}

[SGB]: A história de relações dos povos indígenas com o aparato burocrático estatal no Brasil, como em todos os países onde o Estado se expandiu sobre os territórios dos povos indígenas, tem sido uma história de colonialismo e violência contra os povos indígenas. O exercício do "poder tutelar" sobre os povos indígenas é descrito por Antônio Carlos de Souza Lima (1995) como uma forma reelaborada - com continuidades lógicas e históricas - da "guerra de 
conquista". Este autor define, enquanto modelo analítico, a "conquista" como um empreendimento com distintas dimensões: fixação dos conquistadores nas terras conquistadas, redefinição das unidades sociais conquistadas, promoção de fissões e alianças no âmbito das populações conquistadas, objetivos econômicos e empresa cognitiva. Enquanto Lima (1975) emprega a noção de "poder tutelar", Pacheco de Oliveira (2016) usa a noção de "regime tutelar" referindo-se a uma sociologia dos conflitos.

\section{[LBS]: O senhor tem uma larga experiência em pesquisa antropológica numa perspectiva internacional comparativa. Como surgiu a ideia de comparar os estilos de etnologia praticada no Brasil com aquela desenvolvida em outros países, tais como a Argentina, a Austrália e o Canadá?}

[SGB]: Como mencionei acima, a UnB tornou-se o centro acadêmico que escolhi para consolidar minha carreira e onde desenvolvi minhas pesquisas em etnologia indígena, ampliando o foco, a partir de 1991, a proposta de Roberto Cardoso de Oliveira de "Estilos de Antropologia", para uma pesquisa sobre a etnologia indígena na Austrália (a partir de 1992 com auxílio à pesquisa do CNPq) e, posteriormente, no Canadá (a partir de 1995 com bolsas do governo canadense), e a Argentina a partir de 2016, além de manter pesquisas etnográficas no Brasil sobre nacionalidade e etnicidade entre povos indígenas que vivem em fronteiras internacionais (a partir de 1991), e a criminalização de indígenas no sistema penitenciário de Roraima (a partir de 2008). O estilo de etnologia indígena que se faz no Brasil se tornou o campo em que me inseri e para o qual tenho dedicado minha carreira acadêmica.

O projeto de pesquisa sobre "Estilos de Antropologia", em que a dimensão comparativa da investigação passou a ser efetivada através do estudo do que Cardoso de Oliveira decidiu chamar de "antropologias periféricas" (CARDOSO DE OLIVEIRA, 1988, p. 143-159). Este autor usa este termo para referirse àquelas antropologias situadas na periferia de centros metropolitanos da disciplina (nos centros científicos e acadêmicos onde a antropologia foi gerada e se consolidou como disciplina acadêmica - a Inglaterra, a França e os Estados Unidos da América). Frisa que a justificação maior de um enfoque estilístico sobre as antropologias periféricas está no fato de que a disciplina nos países não metropolitanos não perde seu caráter de universalidade. Cardoso de Oliveira também propôs examinar as tensões que surgem entre uma disciplina 
acadêmica que se pretende internacional enquanto os contextos nacionais em que se pratica são específicos.

Solicitei uma bolsa de produtividade em pesquisa ao CNPq e, a partir de março de 1990, iniciei um projeto de pesquisa para realizar uma pesquisa comparativa sobre a etnologia indígena na Austrália, país onde eu havia passado três meses em 1978-1979, visitando comunidades indígenas no norte e centro daquele país. Participei do projeto de pesquisa coordenado por Cardoso de Oliveira, viajando, no início de 1992, à Austrália para realizar um primeiro levantamento de pesquisa em três de seus principais centros de etnologia indígena: a Universidade de Sydney, a Australian National University (ANU) em Camberra, e a University of Western Australia na cidade de Perth, além de visitar várias outras universidades.

Em 1995, consegui uma bolsa do governo canadense (Faculty Research Programme) para passar cinco semanas no Canadá, realizando um levantamento sobre a etnologia indígena naquele país, como no caso da Austrália, sempre usando a etnologia indígena que se faz no Brasil como ponto de partida. Neste primeiro levantamento, em Montreal, Quebec, realizei visitas à principal universidade francófona, a Université de Montréal, e à principal universidade anglófona, McGill University, além de entrevistar professores de Concordia University. Visitei, também, a Université Laval na cidade de Quebec, e em Toronto, a University of Toronto, além de visitar a University of Waterloo em Ontário. De Toronto, atravessei o Canadá de ônibus à cidade de Kamloops, na província da Colúmbia Britânica, onde visitei o Program of First Nation Studies of the Secwepemc (Shuswap), a Cultural Education Society e a Simon Fraser University (SCES/SFU), em Kamloops; as reservas indígenas Shuswap de Adam's Lake e Skeetchestn; a University of Northern British Columbia (UNBC) na cidade de Prince George; a reserva indígena Witsuwit'en de Moricetown; a University of British Columbia (UBC) e Simon Fraser University em Vancouver; e a University of Victoria na capital da Colúmbia Britânica, Victoria (BAINES, 1996).

Em 2002, consegui outra bolsa do governo canadense (Faculty Enrichment Programme) para passar três semanas em três centros no leste do Canadá Montreal, Ottawa e Toronto, quando aprofundei a pesquisa iniciada em 1995, e em 2009-2010 realizei onze meses de pesquisa de pós-doutorado com bolsa de pós-doutorado da CAPES, cinco meses na University of British Columbia (UBC), no Canadá, de 01 de setembro de 2009 até o final de janeiro de 2010, sob a supervisão acadêmica do professor Bruce Granville Miller, e seis meses na Australian National University (ANU), de 01 de fevereiro de 2010 a 01 de agosto de 
2010, sob a supervisão acadêmica da professora Francesca Merlan. Essas estadias foram períodos de imersão em dois dos principais centros e comunidades acadêmicas em etnologia indígena nestes países, o que permitiu avanços sem precedentes na compreensão da enorme diversidade e complexidade das áreas de etnologia indígenas no Canadá e na Austrália, como também no Brasil. Os onze meses de licença pós-doutoral no Canadá e na Austrália, em 2009-2010, permitiram um enorme avanço em minhas pesquisas sobre estilos de etnologia indígena em contextos nacionais com aprofundamento das reflexões a partir da convivência com comunidades antropológicas nesses dois países.

Para resumir a linha de pesquisa que desenvolvo sobre estilos de etnologia indígena, julgo necessário relatar alguns dos temas trabalhados, apontando os principais autores e ideias que influenciaram minha pesquisa. Nestas pesquisas, parti de uma abordagem comparativa focalizando inicialmente três Estados nacionais: Brasil, Canadá e Austrália, e incluindo Argentina a partir de 2016. A partir de um enfoque nos diferentes contextos históricos, culturais e institucionais em que se desenvolveu a etnologia indígena, analisei algumas das diferenças óbvias na disciplina nos quatro contextos nacionais para depois comparar determinadas semelhanças entre esses quatro países de colonização europeia. Observei, também, tendências associadas a um processo crescente de globalização, que estão aproximando as situações de povos nativos e os estilos de antropologia em projetos de pesquisa colaborativos e participativos por meio de um intercâmbio mais próximo de ideias, com a formação de um número crescente de antropólogos indígenas, além de intelectuais indígenas de distintas áreas acadêmicas. O objetivo desta pesquisa era mostrar como a prática da etnologia indígena está influenciada pelo meio social, cultural e político em que vivem os seus profissionais, e a crescente emergência de uma disciplina que busca tanto uma compreensão universal quanto relevância local. Temas como o papel de "raça" versus "cultura" em definir diferenças; ideologias "hierárquicas" versus "igualitárias"; e ideologias nacionais baseadas em monocultura, bi-cultura e multiculturalismo, foram examinados.

O acréscimo da Argentina, ao realizar uma licença de capacitação naquele país de três meses em 2016, visa o aprofundamento do estudo do estilo de antropologia com povos indígenas em outro país latino-americano muito diferente do Brasil, por meio de novas entrevistas com antropólogos que realizam pesquisas com povos originários naquele país e o acompanhamento de alguns dos seus trabalhos de campo. O objetivo é de comparar os estilos de etnologia indígena que se 
constituíram historicamente em contextos de Estados nacionais diferentes, comparando o estilo de Antropologia Social, focalizando, sobretudo, os estudos realizados junto aos povos indígenas em cada país e investigar a possibilidade de caracterizar um estilo de antropologia junto a povos originários, a partir do estilo de etnologia indígena que se faz no Brasil.

Merece comentar como fiz a passagem de realizar pesquisa em etnologia indígena a um projeto de pesquisa com o objetivo de etnografar os estilos de etnologia em contextos nacionais diversos, ao mesmo tempo em que mantenho pesquisas ativas em etnologia indígena. Em junho de 1989, fiquei decepcionado por ter minha pesquisa junto ao povo indígena Waimiri-Atroari interrompida por uma campanha de calúnias montada por dirigentes do Programa Waimiri-Atroari (ELETRONORTE/FUNAI), como parte de uma proibição a todas as pesquisas independentes em Antropologia junto aos Waimiri-Atroari, feita pelo Programa, assim que assumiu a administração indigenista deste povo indígena. Proibição que começou com a interrupção da pesquisa do professor Márcio Ferreira da Silva, que foi impedido de continuar junto aos Waimiri-Atroari em 1997, após ter realizado sete meses de trabalho de campo para o doutorado no Museu Nacional/UFRJ sob a orientação do professor Eduardo Viveiros de Castro. Em junho de 1989, quando eu era pesquisador do Museu Goeldi, com bolsa de Desenvolvimento Regional do CNPq, indigenistas da direção do Programa Waimiri-Atroari montaram uma campanha de mentiras junto às lideranças Waimiri-Atroari, apresentando-me como se fosse um agente internacional, supostamente trabalhando para empresas mineradoras internacionais e usando os Waimiri-Atroari para tentar impedir que os mesmos indígenas entrassem em acordos diretos com a Mineração Taboca e outras mineradoras do então Grupo Paranapanema. A minha "expulsão" da Terra Indígena Waimiri-Atroari por meio desta campanha de calúnias coincidiu com minha aprovação em concurso público no DAN/UnB em março de 1988. Apesar de aproveitar ao máximo a minha estadia no Museu Paraense Emílio Goeldi em Belém do Pará, experiência muito rica como bolsista do $\mathrm{CNPq}$, aproveitei a oportunidade para me transferir e para assumir o lugar de professor do DAN/UnB em maio de 1989, onde permaneço até hoje, como professor titular desde 2015.

Na campanha feita contra minha presença como pesquisador em etnologia indígena pelo Programa Waimiri-Atroari, uso foi feito de matérias jornalísticas caluniosas publicadas no jornal O Estado de São Paulo ao longo de uma semana, em agosto de 1987, em uma campanha contra o Conselho Indigenista Missionário (CIMI) ligado 
ao Conselho Nacional de Bispos do Brasil (CNBB) - onde eu havia trabalhando em tempo parcial como assistente na biblioteca em 1986-1988 - em que meu nome, alterado na ortografia pelo autor das matérias, entretanto reconhecível, apareceu em duas matérias, me apresentando como se fosse um agente de um cartel de estanho internacional "Tin Brothers da Malásia” (BAINES, 1993).

Apesar de uma Comissão Parlamentar de Inquérito, realizada na segunda metade de 1987, comprovar que as matérias pagas eram falsas e preparadas por Mauro Nogueira, estelionatário então procurado pela Polícia Federal no Pará e no Maranhão, contratado por dois meses pelo então diretor geral do Grupo Paranapanema, Octávio Lacombe (do qual, na época, a Mineração Taboca fazia parte), com a finalidade de montar uma campanha falsa contra o CIMI e pressionar, no período do Constituinte, para a inclusão de uma cláusula na Constituição Federal de 1988 que permitiria mineração em Terras Indígenas por empresas privadas (na Constituição anterior, atividades de pesquisa e lavra de mineração eram restritas a empresas estatais e minérios classificados como estratégicos), dirigentes do Programa Waimiri-Atroari reutilizaram essas matérias. A reutilização foi feita quase dois anos depois de terem sido desmascaradas tais matérias para ludibriar as lideranças Waimiri-Atroari a proibir a minha pesquisa em etnologia sob o pretexto de eu não ser antropólogo, mas agente internacional que, supostamente, teria ludibriado os Waimiri-Atroari ao longo de mais de oito anos de pesquisa, e dezoito meses de pesquisa de campo junto ao povo WaimiriAtroari. Tentei conseguir direito de resposta no Estado de São Paulo e, diante da recusa por parte do jornal, fui encaminhado, na época, ao então procurador Gilmar Mendes no Ministério Público Federal onde o mesmo disse que contra grandes empresas do porte da ELETRONORTE e da Mineração Taboca eu não teria nenhuma possibilidade de ganhar direito de resposta. Sugeriu, inclusive, que evitasse voltar para a Terra Indígena Waimiri-Atroari por algum tempo por minha própria segurança pessoal e, caso viesse a sofrer ameaças em Brasília, deveria procurar novamente o Ministério Público Federal (MPF).

\section{[LBS]: Do que se trata a tua pesquisa sobre indígenas presos no Brasil? O que você destaca de achados relevantes durante sua execução?}

[SGB]: A pesquisa que estou realizando sobre a criminalização de indígenas no estado de Roraima complementa a pesquisa sobre povos indígenas na fronteira 
internacional que venho realizando desde 2001 na fronteira entre Brasil e Guiana, considerando que muitos dos indígenas presos nasceram em Terra Indígenas localizadas ao longo da fronteira, e outros nasceram na Guiana ou são descendentes de indígenas nascidos na Guiana, mantendo laços estreitos com comunidades indígenas nos dois lados da fronteira. Esta linha de pesquisa etnográfica se iniciou em janeiro de 2008, a partir de um levantamento realizado sobre indígenas no sistema penitenciário de Roraima, a convite de um ex-orientando do DAN/ UnB, professor Cristhian Teófilo da Silva, do então CEPPAC/UnB, atual ELA/ UnB, então tesoureiro da Associação Brasileira de Antropologia (ABA) que, na época, estava coordenando um levantamento sobre indígenas presos no Brasil, resultado de um acordo entre a $\mathrm{ABA}$ e o Ministério Público Federal (ABA/ $\mathrm{MPF}$ ). O levantamento em Roraima contou com a colaboração de dois alunos, orientandos meus da pós-graduação em antropologia da UnB a partir de julho de 2008, Alessandro Roberto de Oliveira e Walison Pascoal Vasconcelos. Incorporei à pesquisa sobre a criminalização de indígenas no estado de Roraima, em meu projeto de pesquisa sobre indígenas na fronteira entre Brasil e Guiana, por ter uma relação estreita com a pesquisa sobre indígenas em fronteiras internacionais e migração indígena. Alguns indígenas detentos são nacionais da Guiana, outros são migrantes da Guiana que têm dupla nacionalidade e ainda outros são descendentes de indígenas nascidos na Guiana que habitavam territórios tradicionais na atual região de fronteira desde antes da definição de esta fronteira internacional, em 1904. A questão da fronteira internacional está muito presente na vida cotidiana dos povos indígenas de Roraima, inclusive aqueles presos no sistema penitenciário do estado.

Vários presos indígenas reivindicam um tratamento diferenciado, como penas alternativas, que poderiam ser servidas em Terras Indígenas no caso de ocorrências dentro de Terras Indígenas, com o consentimento das comunidades e dos conselhos dos tuxauas, e/ou uma ala separada nas penitenciárias. Considerando a estrutura desmedidamente assimétrica das relações interétnicas que fundamentam as práticas sociais, policiais e penais, é necessário considerar os obstáculos que os povos indígenas enfrentam para ter acesso à justiça e considerar as possibilidades de criação de instituições diferenciadas como penas alternativas, respeitando seus direitos constitucionais. Esta linha de pesquisa está trazendo algumas mudanças. A pesquisa começou como um levantamento visando contribuir com informações sobre um assunto pouco pesquisado no Brasil e os objetivos buscam contribuir para mudar a situação de extrema injustiça que os indígenas enfrentam nas penitenciárias. Desde janeiro de 2008, quando começamos este estudo, 
alguns indígenas presos no estado de Roraima começaram a exigir seus direitos diferenciados garantidos pela Constituição, o que se tornou assunto de debate nas organizações indígenas, como a Organização de Indígenas na Cidade (ODIC) na capital, Boa Vista, no Conselho Indígena de Roraima (CIR), na Defensoria Pública do estado de Roraima e na própria FUNAI. A possibilidade de criação de uma ala separada dentro das instituições prisionais para abrigar detentos indígenas tornou-se uma proposta do Ministério Público Federal em Roraima.

Apesar de avanços feitos no reconhecimento dos direitos indígenas na Constituição Federal de 1988, e por meio de legislação internacional, como a Convenção 169 da Organização Internacional do Trabalho (OIT), ratificada pelo Brasil em 2002, e a Declaração das Nações Unidas sobre os Direitos dos Povos Indígenas adotada pelo Brasil em 2007, existe um abismo entre a legislação e a prática onde os direitos indígenas são constantemente desrespeitados. Em nenhum lugar isso é mais claro do que no sistema prisional onde prevalecem estereótipos racistas e onde os direitos indígenas continuam a ser desrespeitados. Uso a noção de "criminalização indígena" para abordar o encarceramento de indígenas e a desconsideração dos seus direitos diferenciados.

Esta pesquisa está em andamento, com visitas às unidades penitenciárias do estado de Roraima onde estou acompanhando a vida de indígenas encarcerados e o fluxo de presos indígenas. A continuação e ampliação de pesquisa etnológica sobre a criminalização de indígenas no sistema penitenciário de Boa Vista (RR) está rendendo resultados importantes ao fornecer aos indígenas presos informações sobre seus direitos diferenciados e chamar a atenção de órgãos do governo para a situação de criminalização de indígenas no sistema penitenciário.

A situação nas penitenciárias é de extrema violência e violação de direitos humanos. Em meados de 2019 o Brasil tinha 750 mil presos, 36\% em prisão preventiva, em penitenciárias com graves situações de superlotação e condições sub-humanas, sendo o país com a terceira maior população carcerária do mundo. É impossível obter estatísticas válidas sobre o número de indígenas presos, considerando que o sistema penitenciário e judiciário age para invisibilizar as identidades étnicas subsumidas sob identidades como "de cor parda" seguindo a classificação do Censo Nacional do Instituto Brasileiro de Geografia e Estatística (IBGE). Em Roraima, nos cadastros penitenciários aparecem números muito aquém da realidade, constatável ao entrevistar detentos. 


\section{[LBS]: Como analisa a atual conjuntura da política indigenista? Como observa o papel da FUNAI nesse contexto e o que podemos esperar em termos de transformações da política indigenista?}

[SGB]: A atual conjuntura da política indigenista está muito negativa para os povos indígenas com um governo declaradamente anti-indígena do presidente Jair Bolsonaro que incentiva a invasão de Terras Indígenas para a exploração econômica ampla, inclusive em áreas demarcadas. Desde 2000, uma aliança no Congresso Nacional, entre as bancadas ruralista, evangélica e de mineração constituídas de parlamentares de diferentes partidos, articulou seus esforços para enfraquecer os direitos dos povos indígenas e quilombolas assegurados na Constituição Federal de 1988, por meio de uma série de proposições legislativas - Propostas de Emenda à Constituição (PEC), Projetos de Lei Complementar (PLP), Projetos de Lei (PL), Portarias e Decretos - por parte da bancada ruralista no Congresso Nacional que se autodesigna Frente Parlamentar da Agropecuária (FPA).

Com a eleição do governo do presidente Jair Bolsonaro, aliado ao agronegócio e grandes projetos desenvolvimentistas, os direitos dos povos indígenas estão ameaçados ainda mais, com declarações do presidente favoráveis à expropriação e invasão de territórios indígenas por empresas privadas com interesse em explorar os recursos naturais nas suas terras. Antes de tomar posse, o então candidato à presidência, Bolsonaro, declarou, em 03 de abril de 2017, no Clube Hebraica, no Rio de Janeiro que "Não vai ter um centímetro demarcado para reserva indígena ou para quilombola" e vem sustentando um discurso integracionista que já foi superado há 31 anos pela Constituição Federal de 1988.

Ao tomar posse em 01 de janeiro de 2019, as tentativas do governo Bolsonaro têm sido no sentido de desmontar a FUNAI por meio da Medida Provisória (MP) 870, uma nova estratégia da Frente Parlamentar da Agropecuária para substituir a malsucedida PEC 215, transferindo a demarcação de Terras Indígenas (TIs) para o Ministério da Agricultura, Pecuária e Abastecimento (Mapa), e assim entregando o processo de demarcação à bancada ruralista, junto com outros ataques contra os direitos indígenas.

Desde que tomou posse, o presidente Bolsonaro paralisou mais de 230 processos de demarcação de Terras Indígenas que estão em andamento, em diferentes etapas, em que vivem mais de 120 mil indígenas. Um levantamento realizado, no início de 2019, pelo Instituto Socioambiental (ISA) com a FUNAI revelou pelo menos 40 
empreendimentos de grande porte previstos para invadir essas terras indígenas, incluindo projetos como as hidrelétricas do Tapajós, no Pará, e a construção da linha de transmissão entre Manaus (AM) e Boa Vista (RR), cortando a Terra Indígena Waimiri-Atroari nos estados de Amazonas e Roraima. O povo WaimiriAtroari está sendo submetido a pressões pela empresa Eletronorte, que administra sua Terra Indígena desde 1987 por meio de um Programa Indigenista dentro da própria Eletronorte criada para compensar a inundação de vasta extensão do seu território tradicional pela Usina Hidrelétrica Balbina, para aceitar a construção da linha de transmissão ligando Manaus (AM) a Boa Vista (RR) que cortará cerca de $125 \mathrm{~km}$ da terra indígena com a implantação de 250 torres de transmissão.

As medidas governamentais que visam acelerar o crescimento econômico com aumento da produção de soja e extração de minérios são vistas pelos povos indígenas, quilombolas e outras comunidades tradicionais como ameaças às suas terras tradicionais. Para dar um exemplo, no estado de Roraima, apresentado pelo agronegócio como a nova frente de expansão para o Brasil, em 2019 a previsão da colheita de soja é de 130 mil toneladas, um crescimento das 120 mil toneladas na safra de 2018, comparado com as 75 mil toneladas colhidas em 2016. O site "Notícias Agrícolas", uma das principais fontes de comunicação do agronegócio brasileiro, apresenta Roraima como "a nova fronteira agrícola do Brasil". Isso porque, segundo o governador de Roraima, em 2020, foram plantados 50 mil hectares com soja e 15 mil com milho para a produção prevista de 150 mil toneladas de soja e 110 mil toneladas de milho, números que vêm crescendo $25 \%$ ao ano ao longo dos últimos cinco anos, com expectativa de aumento de até 40\% para 2021 (GOVERNADOR..., 2020).

Outra meta do governo Bolsonaro é a desregulação e desmonte das políticas ambientais no Brasil. As mudanças introduzidas pelo governo atual visam mudanças na composição dos órgãos de meio ambiente, mineração, trazendo efeitos sociais desastrosos com o desmonte da política ambiental sobre territórios e populações, mudanças no procedimento de licenciamento ambiental para facilitar a construção de grandes obras em terras indígenas, favorecendo os grandes empreendimentos na Amazônia brasileira, e os impactos socioambientais nefastos de grandes barragens de usinas hidrelétricas, como Belo Monte, a expansão acelerada da fronteira agropecuária e do agronegócio e a criminalização de movimentos sociais no campo. 
O governo ameaçou retirar o Brasil da Convenção 169 da OIT, visando enfraquecer ainda mais os direitos dos povos indígenas e quilombolas e eliminar a possibilidade de eles recorrerem a esta legislação internacional. A Convenção 169, de 1989, foi aprovada em 19 de junho de 2002 e está em vigor desde 2003, é o principal instrumento internacional que garante o direito de os povos indígenas serem consultados de forma livre, prévia e informada, antes de serem tomadas quaisquer decisões que possam afetar seus bens ou direitos como a implantação de grandes obras desenvolvimentistas em terras indígenas. O governo ameaçou acabar com a Secretaria Especial de Saúde Indígena (Sesai), com 34 distritos sanitários indígenas especiais, que visa trabalhar junto às comunidades locais e atender suas necessidades específicas e diferenciadas.

Além de tentar retirar as competências da FUNAI, da Fundação Palmares e do Instituto Nacional de Colonização e Reforma Agrária (Incra) com definição de poderes para demarcação de terras indígenas e de quilombolas para o Ministério da Agricultura, o governo extinguiu no Ministério do Meio Ambiente, o departamento responsável pela condução das políticas de prevenção e controle dos desmatamentos na Amazônia e demais biomas, com imediato crescimento do desmatamento, além de várias medidas que subordinam a agenda socioambiental à agenda econômica. O desmonte do Estado pelo governo Bolsonaro também beneficia a liberação de muitos agrotóxicos proibidos em vários países do mundo, além de liberar a porte de armas e incentivar os fazendeiros a se armarem.

A política indigenista do governo Bolsonaro é a pior desde a ditadura militar e continua lançando estratégias para atacar os direitos indígenas. A Instrução Normativa No. 9, de 16/04/2020, da presidência da FUNAI, exclui as terras indígenas que não têm seus processos de homologação finalizados do Sistema de Gestão Fundiária (SIGEF), colocando mais de 237 terras Indígenas, de um total de 723 , em perigo de serem vendidas, invadidas, desmembradas e loteadas. Mais uma estratégia deste governo para atacar e tentar desmontar os direitos indígenas. A FUNAI vem sofrendo cortes do orçamento e se encontra em uma situação com grave déficit de funcionários para dar conta de demandas crescentes, deixando-a como órgão profundamente enfraquecido. Sempre foi difícil lidar com a FUNAI, pois apesar de ter algumas pessoas altamente competentes e com as melhores intenções que trabalham na FUNAI, as ordens que vêm de cima, orientadas para interesses desenvolvimentistas, frequentemente atropelam os esforços daqueles servidores que lutam pela efetivação dos direitos indígenas. 


\section{[LBS]: Qual a tua análise sobre as atuais políticas governamentais para a} região amazônica?

[SGB]: As atuais políticas governamentais para a região amazônica anunciam um desastre com o desmonte da legislação indigenista e ambientalista, visando abrir a Amazônia para agronegócio, mineração, a construção de usinas hidrelétricas e outros empreendimentos. O governo atual vem acelerando o desmatamento, os incêndios florestais, as invasões de terras indígenas, os assassinatos de lideranças e outras violências contra os povos indígenas. $\mathrm{Na}$ minha pesquisa na região do Lavrado de Roraima, presenciei ao longo dos últimos 19 anos o avanço do agronegócio com uma velocidade assustadora, deixando muitas das terras indígenas fragmentadas, entre plantações de soja e sem espaço para abrigar suas populações crescentes, além de situações como aquela em que se encontra a comunidade do Anzol, que ainda não foi demarcada, deixando os habitantes encurralados em uma pequena faixa de terra entre pretensas fazendas, projetos de assentamento, plantações de acácia e ocupações por posseiros.

\section{[LBS]: Qual é sua agenda de pesquisa para os anos vindouros?}

[SGB]: Pretendo continuar as pesquisas que estou realizando, sempre atualizandoas e ampliando conforme as novas situações que se apresentam, orientando estudantes da Pós-Graduação no DAN/UnB e no ELA/UnB, estudantes da Graduação do DAN, e do Programa de Iniciação Científica (PIBIC) do DAN, e supervisionando pesquisadores pós-doutorandos, elaborando meus projetos de pesquisa, publicando, e participando de eventos acadêmicos nacionais e internacionais com a organização de simpósios e apresentação de trabalhos individuais. Pretendo continuar a realizar pesquisas que sejam úteis para os próprios povos indígenas. O ingresso de estudantes indígenas no PPGAS/DAN tem sido muito estimulante. No momento estou orientando cinco estudantes indígenas no PPGAS/DAN que está sendo uma experiência inédita.

[LBS]: Por fim, que tipo de conselho daria a um jovem pesquisador interessado em iniciar seus estudos sobre povos indígenas e política indigenista numa perspectiva comparada? Por onde começar?

[SGB]: O conselho que eu daria a um(a) jovem pesquisador(a) é de conseguir uma base teórica sólida em sua área, incluindo uma formação em antropologia, 
mesmo que o(a) jovem venha de outra área, e realizar o maior período de pesquisa de campo possível, pois sem a experiência de pesquisa de campo junto a um povo indígena os resultados serão sempre limitados. Quando realizei o doutorado, fiz todo o esforço para realizar o mais tempo possível em pesquisa de campo e consegui permanecer 18 meses junto ao povo Waimiri-Atroari, que certamente foi uma das experiências mais interessantes da minha vida. Pois são as situações de campo, em que convivemos com povos indígenas, os momentos mais ricos para refletir sobre as realidades indígenas. Como também estão sendo minhas pesquisas de campo atuais junto a Makuxi e Wapichana na fronteira Brasil-Guiana e junto a indígenas presos nas penitenciárias de Roraima. As situações de pesquisa de campo são muito complexas, onde o(a) pesquisador(a) lida não apenas com povos indígenas, mas com a presença de grandes projetos desenvolvimentistas e grandes empresas em situações frequentemente de conflitos fundiários extremamente violentos. Nada substitui a pesquisa de campo e o contato face a face com as pessoas, seja com indígenas, seja com antropólogos que realizam pesquisas junto a povos indígenas, no caso de estudos sobre estilos de antropologia.

\section{REFERÊNCIAS}

BAINES, S. G. É a FUNAI que sabe: a frente de atração Waimiri-Atroari. Belém: Museu Paraense Emílio Goeldi/ CNPq/ SCT/ PR, [1988] 1991a. (Coleção Eduardo Galvão).

BAINES, S. G. Etnologia e indigenismo na Austrália. Série Antropologia, Brasília, DF, n. 115, p. 1-19, 1991 b.

BAINES, S. G. O território dos Waimiri-Atroari e o indigenismo empresarial.

Ciências Sociais Hoje, [s. l.], n. 138, p. 219-243, 1993.

BAINES, S.G. Etnologia indígena no Canadá: primeiras impressões. Série Antropologia, Brasília, DF, n. 196, p. 1-39, 1996.

BAINES, S. G. Waimiri-Atroari: resistance in the presence of an indigenist policy of 'resistance'. Critique of Anthropology, [s. l.], v. 19, p. 211-226, 1999.

BAINES, S. G. Imagens de liderança indígena e o Programa Waimiri-Atroari: índios e usinas hidrelétricas na Amazônia. Revista de Antropologia, São Paulo, v. 43, p. 141-163, 2000. 
CARDOSO DE OLIVEIRA, R. A sociologia do Brasil indígena. Brasília, DF: Editora UnB; Rio de Janeiro: Tempo Brasileiro, 1978.

CARDOSO DE OLIVEIRA, R. O índio e o mundo dos brancos. 3. ed. Brasília, DF: Editora UnB; São Paulo: Pioneira, [1964] 1981.

CARDOSO DE OLIVEIRA, R. Sobre o pensamento antropológico. Rio de Janeiro: Tempo Brasileiro; Brasília, DF: CNPq, 1988.

GOVERNADOR de Roraima destaca safra recorde de soja e milho em 2020 e espera crescimento de 40\% do setor para 2021. Notícias Agrícolas, [s. l.], 04 set. 2020. Disponível em: https://www.noticiasagricolas.com.br/videos/ soja/267938-governador-de-roraima-destaca-safra-recorde-de-soja-e-milho-em2020-e-espera-crescimento-de-40-do-setor.html\#.X478NdBKiM8. Acesso em: 12 ago. 2021.

LIMA, A. C. S. Um grande cerco de paz: poder tutelar, indianidade e formação do Estado no Brasil. Petrópolis, RJ: Vozes, 1995.

PACHECO DE OLIVEIRA, J. O nascimento do Brasil e outros ensaios: "pacificação", regime tutelar e formação de alteridades. Rio de Janeiro: Contra Capa, 2016. 
